\title{
Current management options in metastatic renal cell cancer
}

\author{
Sittu Govindasamy Dinakaran Gangadaran \\ Medical Oncology, Govt. Royapettah Hospital, Chennai, India
}

\begin{abstract}
Renal cancer accounts for $2.4 \%$ of all cancers. Localised disease accounts for the majority of renal cancers (70-75\%), however $20-25 \%$ of these ultimately develop distant metastasis. The median overall survival of un treated metastatic disease is 5 months with 1 -year survival of only $29 \%$. The management of metastatic renal cell cancers traditionally relied on systemic immunotherapy with attendant high morbidity but after the year 2005 the use of effective targeted therapy with tolerable side effect profile has improved the survival from 10.2 months in the cytokine era to 17.7 months. This article reviews the past, present and future options in the management of metastatic renal cancer.
\end{abstract}

\section{Introduction}

Renal cancer (RCC) currently ranks twelfth among other cancers in incidence, a position it holds along with pancreatic cancer. A lifetime risk of 1 in $63(1.6 \%)$ has been reported for the general population with a median age of 65 years at diagnosis. GLOBOCAN 2012 data indicate renal cancer accounts for $2.4 \%$ of all cancers. ${ }^{1}$ The age-standardised rate worldwide is 4.4 per 100,000 population with males ( 6 per 100,000) more commonly afflicted than females (3 per 100,000). ${ }^{2}$ North America and Europe have a reported higher incidence compared to Africa and Asia with Czech Republic and Lithuania reporting an age standardised rate of 16.7 and 13.2 per $100,000 .^{3}$ Time trends indicate an increasing incidence from 1975-2009, primarily due to detection of localised disease with incidence of distant disease remaining unchanged. The

Correspondence: Sittu Govindasamy Dinakaran Gangadaran, Medical Oncology, Govt. Royapettah Hospital, Chennai, India

Tel.: +91.9841096885.

E-mail: Sgd_gangadaran@rediffmail.com

Key words: Renal cancer; metastatic disease; targeted therapy; immunotherapy.

Conflict of interest: the author declares no potential conflict of interest.

Received for publication: 3 April 2017.

Revision received: 7 May 2017.

Accepted for publication: 31 May 2017.

This work is licensed under a Creative Commons Attribution NonCommercial 4.0 License (CC BY-NC 4.0).

(C) Copyright S.G.D. Gangadaran, 2017

Licensee PAGEPress, Italy

Oncology Reviews 2017; 11:339

doi:10.4081/oncol.2017.339 mortality rates increased between 1975-2004 but have now since stabilised. ${ }^{4}$

\section{Natural history of metastatic renal cancer}

The 10 major histological types of renal cancer result in considerable variability in the natural history of the disease and this reflects in the five year survival rates which vary from $81 \%$ for stage I disease to only $8 \%$ for metastatic disease. ${ }^{5}$ Localised disease accounts for the majority of renal cancers (70-75\%), however $20-25 \%$ of these ultimately develop distant metastasis. The median overall survival of un treated metastatic disease is 5 months with 1 yr survival of only $29 \% .{ }^{6}$ RCC commonly metastases to lung $(60 \%)$, bone $(30 \%)$, liver, lymph nodes and the brain. The prognosis is known to vary with the involved target organ, liver and bone involvement resulting in adverse survival compared to lung and lymph nodal disease. This observation initially noted during the cytokine era has been reported to be unchanged with the targeted therapy regimes as well. Kroeger et al reported poor survival in patients with nodal involvement and recommended lymph nodal dissection during cytoreductive nephrectomy. ${ }^{7}$ The treatment of metastatic renal cell cancers traditionally relied on systemic immunotherapy with its attendant high morbidity but after 2006 the use of effective targeted therapy with tolerable side effect profile has improved the survival from 10.2 months in the cytokine era to 17.7 months with targeted therapy.

\section{Molecular biology of renal cancer}

Our knowledge of the abnormal molecular pathways involved in renal cancer genesis is attributed to study of hereditary renal cancers. Mutations in the Von Hippel Lindau (VHL) gene are the primary defect in $92 \%$ of sporadic and all hereditary clear cell cancers. The hereditary papillary, chromophobe and oncocytic tumors have defective MET and folliculin (FLCN) genes respectively but the sporadic variants of these types exhibit these abnormalities in only $13 \%$ and $11 \%$ of tumours. ${ }^{8}$ The VHL gene product binds to hypoxia inducible factor $(\mathrm{HIF}-\alpha)$ and targets it for ubiquitin mediated degradation. In clear cell cancers inactivating mutation of the VHL protein inhibit HIF- $\alpha$ degradation allowing accumulation of HIF- $\alpha$. HIF- $\alpha$ function as a transcription factor and up regulates its target genes like VEGF, PDGF and GLUT-1 resulting in neovascularisation and tumor growth. The mTOR pathway functions in the downstream of PI3-K/Akt pathway and through its effector S6K regulates cell growth and proliferation in response to growth factors, nutrient, energy level and environmental stresses. Inactivating mutations of the FLCN gene negatively regulates the mTOR pathway. The MET proto-oncogene codes for hepatocyte growth factor (HGF) hence activating mutation as in papillary tumors promote cell growth, morphogenesis and differentiation. ${ }^{8}$ 
Targeting each of these pathways presents promising treatment strategies in advanced renal cancer. Targeting strategies include multistep inhibition of a single pathway (vertical) or single step inhibition of multiple pathways (horizontal).

\section{Risk stratification in renal cancer}

The varied spectrum of biological behaviour of renal cancer coupled with a myriad of approved targeted therapy makes selection of appropriate therapy for an individual patient difficult. The use of prognostic or predictive factors can help circumvent this issue but each approach has its own inherent limitations. Several prognostic models like the MSKCC risk model, the Cleveland clinic foundation $(\mathrm{CCF})$ model, Groupe Francais d'Immunotherapie (French) model, the IKCWG model and the International Metastatic IMDC model have been reported. The Motzer (MSKCC) model uses low Karnofsky performance status ( $\mathrm{PS}<80 \%$ ), high serum lactate dehydrogenase ( $\mathrm{LDH}>1.5$ times upper limit of normal-ULN), low hemoglobin ( $\mathrm{Hb}<$ lower limit of normal-LLN), high corrected serum calcium $(>10 \mathrm{mg} / \mathrm{dL})$, and time since diagnosis and treatment initiation $<1$ year to stratify patients with metastatic into good risk ( 0 risk factors), intermediate (1-2 risk factors) and poor risk groups. ${ }^{9}$ Mekhail et al. added prior radiotherapy and number of metastatic sites to motzers criteria and subsequently validated the same (CCF model). ${ }^{10}$ The French model uses presence of hepatic metastases, short interval from renal tumor to metastases ( $<1$ year), more than one metastatic site and elevated neutrophil counts (ANC) as prognostic determinants and patients who combined at least three of these factors have $>80 \%$ probability of rapid progression despite treatment. ${ }^{11}$ The Heng model (IMDC) excludes serum LDH from the motzer model but includes high neutrophil and platelet counts to stratify risk similar to the motzer model. ${ }^{12}$ The IKCWG model uses performance status, number of metastatic sites, time from diagnosis to treatment, and pre treatment hemoglobin, white blood count, lactate dehydrogenase, alkaline phosphatase, and serum calcium into a risk score that is subsequently used to stratify patients into good, intermediate and poor risk groups. ${ }^{13}$ It is important to note while the motzer model was developed for use in the cytokine era, the IKCWG and CCF models have been tested on patients treated with targeted therapy and have been found to be valid. $1^{4}$ The motzer and the Heng model have been used in the inclusion of study participants in the management defining clinical trials and consequently a working knowledge of risk stratification is essential for selection of appropriate therapy in practice. A tabulated summary of each model is presented in Table 1 for quick review.

\section{Surgical management}

Surgical options include cytoreductive nephrectomy, metastatectomy and local therapies including radiotherapy. The benefit of cytoreductive nephrectomy in combination with cytokine therapy has been proved in several phase III trials. The southwest oncology group reported a $31 \%$ reduction in the risk of death in the nephrectomy plus interferon $\alpha 2 \mathrm{~b}$ arm compared to interferon only arm (13.6 vs 7.8 months median survival). ${ }^{15}$ The European genito urinary group in a similar study design demonstrated a17 vs 7 months survival benefit to the interferon $\alpha 2 \mathrm{~b}$ and nephrectomy arm. ${ }^{16}$ An identical benefit has been noted with interleukin-2 and cytoreductive nephrectomy. ${ }^{17}$ The ideal candidature for this combined therapy has been a source of considerable debate. It is generally accepted that a resectable tumor, performance status 0 or 1 , lung only metastasis, good risk status as ascertained by the motzer criteria and absence of brain, bone and liver metastasis identify the cohort that derives the best results from this therapy. It is important to note despite a survival benefit, cytoreductive nephrectomy is associated with higher morbidity and mortality. Abdollah et al. after a database review of 1063 patients reported higher mortality (2.4\%vs $0.9 \%)$, longer hospital stay ( 8.4 vs 5.7 days), higher second procedure (28\% vs $10 \%)$, and post op complications $(26 \%$ vs $19 \%$ ) in the nephrectomy patients. ${ }^{18}$ Advanced age $\geq 75$ years and comorbidity score of $\geq 3$ was associated with poor outcomes, hence despite recommendations a prudent clinical decision after thorough discussion with the patient is required. ${ }^{19}$ It is noteworthy that the above benefit has been noted in clear cell histological type only. No phase III prospective trial data exists for combining nephrectomy with targeted agent, however several retrospective data indicate a benefit of $19.8 v s 9.4$ months while combining cytoreductive nephrectomy with VEGF targeted therapy. ${ }^{20}$

Approximately $1.5-3 \%$ of patients have solitary metastasis and

Table 1. Prognostic models in advanced RCC.

\begin{tabular}{|c|c|c|c|c|}
\hline Prognostic factor & MSKCC Motzer & CCF & HENG & IKCWG \\
\hline Time from RCC diagnosis to start of therapy $<1 \mathrm{yr}$ & + & + & + & + \\
\hline PS $<80 \%$ Karnofsky & + & + & + & + \\
\hline Sr LDH $>1.5 X$ ULN & + & - & - & + \\
\hline Corrected Serum ca $>$ ULN & + & + & + & + \\
\hline $\mathrm{Hb}<\mathrm{LLN}$ & + & - & + & + \\
\hline Prior RT & - & + & - & - \\
\hline$>2$ metastatic sites & - & + & - & + \\
\hline ANC $>$ ULN & - & - & + & + \\
\hline Platelet $>$ ULN & - & - & + & - \\
\hline Prior immunotherapy & - & - & - & + \\
\hline Elevated alkaline phosphatase & - & - & - & + \\
\hline Risk category & $\begin{array}{c}\text { Good }=0 \\
\text { Intermediate }=1 \text { or } 2 \\
\text { Poor }=>2\end{array}$ & $\begin{array}{c}\text { Favourable }=0 \text { or } 1 \\
\text { Intermediate }=2 \\
\text { Poor }=>2\end{array}$ & $\begin{array}{c}\text { Favourable }=0 \\
\text { Intermediate }=1 \text { or } 2 \\
\text { Poor }=>2\end{array}$ & $\begin{array}{c}\text { Fav }=\text { RS }<-2.75 \\
\text { Inter }=>-2.75 \leq-1.25 \\
\text { Poor }=>-1.25\end{array}$ \\
\hline
\end{tabular}


can be considered for metastatectomy. A survival advantage has been demonstrated in retrospective studies when such surgery has been combined with immunotherapy. Metastatectomy is done with a curative intent and is generally preceded or combined with radical nephrectomy. Metastatectomy has been reported for several organs including lung, bone and brain metastasis, however lung metastasis has been observed to have better overall survival compared to other sites. No clear selection criteria are recommended but good performance status, a completely resectable lesion preferably lung metastasis and absence of major comorbidities indicate an ideal surgical candidate. ${ }^{19}$

\section{Systemic therapy}

\section{Chemotherapy}

Systemic therapy for metastatic renal cancer was long considered ineffective as early trials with medroxy progesterone and chemotherapy with 5FU failed to demonstrate significant antitumor effects. A review of 51 phase II trials that included 33 chemotherapy drugs showed an overall response rate of only $5.5 \%{ }^{19}$ Recently combination chemotherapy with $5 \mathrm{FU}$ and gemcitabine has been reported to have a response rates of $10-15 \%$ in phase II trials. ${ }^{21}$ The addition of 5FU to immunotherapy has failed to improve survival in phase III trials. ${ }^{22}$

\section{Cytokine therapy}

Interleukin-2 (IL-2) and interferon $\alpha-2 b$ (IFN) represented the standard of care until the advent of targeted therapy in 2005. IL-2 has been in use to treat renal cancer since 1985 with response rate varying from $7-27 \%$. High dose IL-2 in a dose of $600,000 \mathrm{IU} / \mathrm{Kg}$ for 14 doses or $720,000 \mathrm{IU} / \mathrm{Kg}$ for 12 doses every 8 hourly per week produced complete response in $7 \%$ that was maintained for a median of 80 months. Substantial toxicity was the major limitation with $3-4 \%$ succumbing to therapy related mortality. In current practice high dose IL-2 though listed as first line therapy in patients with good performance status, lung metastasis and clear cell histology is not preferentially used in lieu of targeted therapy. ${ }^{19}$ IFN monotherapy produces responses similar to hormonal agents with response rate of 6-15\%. A Cochrane meta analysis confirmed a moderate benefit compared to placebo but the response was not reproducible in the intermediate risk category. ${ }^{19}$ Combination of IFN 9MU three times a week with bevacizumab $10 \mathrm{mgs} / \mathrm{kg}$ biweekly is an approved first line therapy in metastatic clear cell renal cancer in patients with favourable risk assessment.

\section{Targeted therapy}

Pazopanib is an oral anti angiogenic tyrosine kinase inhibitor approved for first line therapy and in patients progressive after IFN therapy. It is also effective against PDGFR $\alpha, \beta$ and cKit. The VEG 105192 trial tested pazopanib $800 \mathrm{mgs} /$ day against placebo in both treatment naive and patients progressing on IFN, with $89 \%$ of study participants nephrectomised in both arms. A significant PFS survival advantage to pazopanib was demonstrated (9.2 vs 4.2 months, HR 0.46), the benefit was larger in treatment naive (11.1 vs 2.8, HR 0.40) compared to those receiving prior cytokines (7.4 $v s$ 4.2, HR 0.54). The trial design permitted crossover which may have confounded the non significant overall survival results (22.9 vs 20 months). Treatment discontinuation due to adverse effects was only $14 \%$ with diarrhoea (52\%), nausea (26\%) and haematological toxicity (32\%) commonly reported. The commonest grade $3 / 4$ toxicity was hypertension (40\%). Toxicities were manageable by dose reduction to $400 \mathrm{mgs}$ and subsequent increments done in 200 mgs steps. ${ }^{23}$ The COMPARZ, non-inferiority trial tested pazopanib $800 \mathrm{mgs} /$ day against sunitinib $50 \mathrm{mgs} /$ day in a 4 week on 2 week off cycle in treatment naive patients. Pazopanib was found to be non-inferior as assessed with the primary end point of PFS (8.4 vs 9.5 months) and with overall survival (28.3 vs 29.1 months). Pazopanib was found to be less toxic with lower fatigue, hand foot syndrome, and thrombocytopenia, and had better patient acceptability with only $24 \%$ discontinuing due to adverse effects. Treatment related mortality was identical at $1 \%$ in both groups. The side effects were managed by dose decrements of $200 \mathrm{mg}$ for pazopanib and $12.5 \mathrm{mgs}$ for sunitinib. ${ }^{24}$ The PISCES crossover study tested patient preference between pazopanib and sunitinib and confirmed better patient preference for pazopanib over sunitinib. ${ }^{25}$

Sunitinib is a multi tyrosine kinase receptor inhibitor effective against VEFR,PDGFR and cKIT. It was one of the first targeted therapy (2006) to be approved for metastatic renal cell carcinoma in cytokine refractory patients and in those with no prior therapy. A multicenter international study compared standard dose sunitinib with IFN in treatment naive metastatic RCC. Nephrectomy rates approached $90 \%$ and $77 \%$ had more than 2 metastatic sites. An interim analysis with PFS endpoint favoured the sunitinib arm (11 vs 5 months, HR 0.41) subsequently the trial permitted crossover not surprisingly an overall survival benefit remained insignificant (114 vs 95 weeks, HR 0.82). Adverse event were more in the sunitinib arm but grade $3 / 4$ toxicities were identical in both arms. Side effects requiring dose reductions were more frequent in the sunitinib arm (32 vs 21\%). Despite more general adverse effects with sunitinib quality of life parameters favoured sunitinib $(\mathrm{P}<0.001){ }^{26}$ The EFFECT trial tested sunitnib in standard dosing schedule with a modified dose of $37.5 \mathrm{mgs} /$ day continous regime. The time to progression was longer with the standard dosing schedule with identical tolerability with either scheduling. ${ }^{27}$ Sunitinib in a $2 / 1$ dosing schedule has been recently proven to be less toxic than the standard 4/2 dosing schedule with preserved oncological benefits (RESTORE TRIAL). ${ }^{28}$

Sorafenib was the first TKI to be licensed for metastatic renal carcinoma. Escudier et al. in a multi center international phase III trial (TARGET) compared sorafenib with placebo in intermediate and low risk groups (MSKCC risk) with metastatic clear cell renal cancer in a dose of $400 \mathrm{mgs}$ twice daily in 6 weekly cycles for first 24 weeks followed by 8 weekly cycles. $93 \%$ had prior nephrectomy and $81 \%$ had received cytokine therapy with either IL-2 or IFN. A PFS advantage to sorafenib (5.5 vs 2.8 months, $\mathrm{P}<0.001)$ was noted at interim analysis and the benefit also translated into a non-significant overall survival trend (19.3 vs 15.9 months, $\mathrm{P}=0.02)$. Ten and $8 \%$ discontinued treatment due to adverse effects in each arm. Dose reductions (13\% vs 3\%) and dose interruptions $(21 \%$ vs $6 \%)$ were more with sorafenib. The dose reduction protocol was $400 \mathrm{mgs} /$ day as initial step, further reducing to alternate day treatment. Two treatment related deaths was reported in the sorafenib arm. ${ }^{29,30}$ The PREDICT multicenter non interventional study was done to evaluate safety and efficacy of sorafenib in the practice setting. Advanced renal cancer and absence of contra indication to sorafenib were the inclusion criteria and the study did not have specific disease related exclusion criteria. This study confirmed tolerability and efficacy of sorafenib, the median PFS was 7.3 months but no overall survival data was reported. The study consequent to its heterogeneous inclusion criteria was able to demonstrate a benefit in poor risk, brain metastasis and non clear cell histology all excluded in the previously reported phase III TARGET trial. ${ }^{31}$ It is important to note the efficacy was assessed by the investigators using subjective criteria as opposed to contem- 
porary practice of using the RECIST criteria. A phase II trial evaluated sorafenib against IFN in treatment naive metastatic renal cancer and failed to show a benefit to sorafenib, however this trials showed a dose dependant response to sorafenib as patients progressing on a dose of $400 \mathrm{mgs}$ showed a good response after increasing the dose to $600 \mathrm{mgs}$ twice daily. ${ }^{32}$ Sorafenib continues to be the standard arm in several phase III trials testing third or second line agents and has been tested against tivozanib and dovitinib both found to be not superior to sorafenib. . $^{33,34}$

The monoclonal antibody against VEGF, bevacizumab adminstered $10 \mathrm{mgs} / \mathrm{kg}$ every 2 weeks with IFN 9MU thrice a week is an established first line therapy in the favourable and intermediate risk groups. The AVOREN trial tested this combination with IFN alone and demonstrated a PFS benefit of 10.2 vs 5.4 months (HR $0.63, \mathrm{P}<0.001)$, but the long term results with regards to overall survival was not significant (23.3 vs 21.3 months), the authors hypothesizing lack of OS benefit to confounding by post progression second line therapy. ${ }^{35}$ The CALGB 90206 had an identical design except not requiring a placebo in the IFN arm and in not requiring a prior nephrectomy. The results were similar to the AVOREN with a significant PFS benefit (8.5 vs 5.2 months) but no OS benefit. ${ }^{36}$ In both trials the combined arms had more toxicity related issues with fatigue, anorexia, hypertension and proteinuria dominating. The exact contribution of IFN to the efficacy of the combination together with the mechanism of action remains unknown. Bevacizumab monotherapy has been tested only in phase II trials and a median PFS of 8.5 months noted. ${ }^{37}$

Axitinib is a second generation TKI against VEGFR offering greater potency and specificity in inhibition. It is currently approved as a first, second and third line agent in metastatic renal cancer. The phase III AXIS evaluated axitinib $5 \mathrm{mgs}$ twice daily against sorafenib $400 \mathrm{mgs}$ twice daily on patients with prior cytokine and VEGFR antagonist exposure. The PFS was longer in axitinib (8.3 vs 5.7 months, HR 0.65) but no OS advantage was demonstrable (20.1 vs 19.2 months, HR 0.96). Patient reported outcomes and toxicity related variables were identical in both groups with only $4 \%$ treatment discontinuation rate. The quantum of benefit was longer in the cytokine subgroup compared to sunitnib subgroup perhaps indicating lack of resistance to VEGFR inhibitors. ${ }^{38}$ A similar clinical activity was observed in third line setting also. ${ }^{39}$ In treatment naive patients axitinib compared to sorafenib showed a non significant trend towards better median PFS (10 vs 6.4 months) establishing clinical activity with acceptable toxicity profile. $^{40}$

Two mTOR inhibitors, temsirolimus and everolimus are approved for use in renal cancer, particularly for VEGF refractory disease. The Global advanced renal cell carcinoma phase III tested temsirolimus 25 mgs weekly with IFN 3 MU thrice weekly escalated to $18 \mathrm{MU}$ or combination of temsirolimus $15 \mathrm{mgs}$ weekly plus IFN $3 \mathrm{MU}$ thrice weekly escalated to 6MU. Inclusion criteria required any histology, no prior therapy and at least 3 of 6 risk factors (poor risk). 18\% had non-clear cell histological types. The Median OS was 10.9,7.3 and 8.4 months for temsirolimus, IFN and combination arms, however despite a significant PFS advantage and OS benefit could not be demonstrated. Toxicity profile $(67 \%$ vs $78 \%$ vs $87 \%$ ) favoured the temsirolimus arm, it is important to note the dose of IFN used was higher than in other trials. The best results were observed in age $<65$ years and in the clear cell type. ${ }^{41}$

Table 2. Practice points on clinical pharmacology of selected targeted agents.

\begin{tabular}{|c|c|c|c|c|c|c|}
\hline & Pazopanib & Sunitinib & Sorafenib & Axitinib & Everolimus & Temsirolimus \\
\hline Dose & $\begin{array}{l}800 \text { mgs/day } \\
1 \text { h before } \\
2 \text { h after food }\end{array}$ & $\begin{array}{c}50 \mathrm{mgs} / \text { day } \\
\text { 4week on } 2 \text { week } \\
\text { off or } 2 \text { week } \\
\text { on } 1 \text { week off }\end{array}$ & 400 mgs BD & $\begin{array}{l}5 \text { mgs BD } \\
\text { without food } \uparrow \text { to } 7 \mathrm{mgs} \\
\text { BD then to } 10 \mathrm{mgs} \\
\text { BD every } 2 \text { weeks }\end{array}$ & 10 mgs OD & $\begin{array}{l}25 \mathrm{mgs} / \text { wkly } \\
\text { IV }\end{array}$ \\
\hline $\begin{array}{l}\text { Dose modification } \\
\text { protocol }\end{array}$ & $\begin{array}{l}400 \text { mgs/day then } \\
\text { in } 200 \text { mgs steps }\end{array}$ & $\begin{array}{c}12.5 \mathrm{mgs} \\
\text { decrements }\end{array}$ & $\begin{array}{l}400 \text { mgs OD then to } \\
\text { alternate day }\end{array}$ & 3 mgs or 2 mgsBD & $\begin{array}{l}2.5 \text { mgs OD then } \\
\uparrow \text { to } 5 \text { mgs OD il }\end{array}$ & $\begin{array}{l}\text { Restart at } 5 \mathrm{mgs} / \mathrm{wk} \\
\text { increase to } 15 \mathrm{mgs} / \mathrm{wk}\end{array}$ \\
\hline \multicolumn{7}{|l|}{ Interactions } \\
\hline $\begin{array}{l}\text { CYP3A4 inhibitors } \\
\text { CYP3A4 inducers }\end{array}$ & $\downarrow$ dose to $400 \mathrm{mgs}$ & $\begin{array}{l}37.5 \mathrm{mgs} \\
87.5 \mathrm{mgs}\end{array}$ & $\downarrow$ dose & 5 mgs BD & $\downarrow$ dose & $\begin{array}{l}12.5 \mathrm{mgs} / \mathrm{wk} \\
50 \mathrm{mgs} / \mathrm{wk}\end{array}$ \\
\hline Renal dysfunction & $\begin{array}{l}\text { No dose reduction } \\
\text { till Cr clearance } \\
\quad<30 \mathrm{ml} / \mathrm{min}\end{array}$ & $\begin{array}{l}\text { None even in severe } \\
\text { impairment }\end{array}$ & None required & None required & None & Stop therapy \\
\hline $\begin{array}{l}\text { Hepatic dysfunction } \\
\text { Child A } \\
\text { Child B }\end{array}$ & $\begin{array}{l}\text { No change } \\
200 \text { mgs/day }\end{array}$ & $\begin{array}{l}\text { No change } \\
\text { No change }\end{array}$ & $\begin{array}{l}\text { No change } \\
\text { No change }\end{array}$ & $\begin{array}{c}\text { No change } \\
50 \% \downarrow\end{array}$ & $\downarrow$ dose & $\downarrow$ dose \\
\hline Cardiac dysfunction & $\begin{array}{c}\text { Stop if LVEF } \downarrow>15 \% \\
\text { cQT interval } \\
>50 \mathrm{msec}\end{array}$ & $\begin{array}{c}\text { Stop if LVEFR >15\% } \\
\text { cQT interval } \\
>50 \mathrm{msec}\end{array}$ & Cardiac ischemia/ CCF & None required & None required & None required \\
\hline Monitoring therapy & $\begin{array}{l}\text { BP- weekly } \\
\text { LFT Bi weekly } \\
\text { LVEF } \\
\text { TFT } \\
\text { Urine protein }\end{array}$ & $\begin{array}{c}\text { BP-weekly } \\
\text { LFT each cycle } \\
\text { LVEF } \\
\text { TFT }\end{array}$ & $\begin{array}{l}\text { BP-weekly } \\
\text { LFT Biweekly } \\
\text { LVEF } \\
\text { TFT } \\
\text { Urine protein }\end{array}$ & $\begin{array}{c}\text { BP-weekly } \\
\text { LFT 2weekly } \\
\text { TFT } \\
\text { Urine protein }\end{array}$ & $\begin{array}{c}\text { CBC weekly } \\
\text { RFT } \\
\text { Lipid } \\
\text { Glucose Bi weekly }\end{array}$ & $\begin{array}{c}\text { CBC weekly } \\
\text { RFT, LFT } \\
\text { Glucose, } \\
\text { lipid profile levels } \\
\text { Bi weekly } \\
\text { CXR }\end{array}$ \\
\hline Comments & PPI $\downarrow$ absorption by $40 \%$ & $\begin{array}{l}\text { Caution in bleeding } \\
\text { or perforation }\end{array}$ & $\begin{array}{l}\text { Caution in bleeding } \\
\text { or perforation risk } \\
\text { risk hypoglycemia }\end{array}$ & $\begin{array}{l}\text { Avoid in GI bleed } \\
\text { or perforation risk }\end{array}$ & $\begin{array}{l}\text { Watch for pnemonitis } \\
\text { and infections }\end{array}$ & $\begin{array}{c}\text { Watch for } \\
\text { interstitial lung } \\
\text { disease, } \\
\text { bowel perforations, } \\
\text { and infections }\end{array}$ \\
\hline
\end{tabular}


The INTORSECT trial evaluated temsirolimus against sorafenib in patients failing on sunitinib, no PFS difference was demonstrable but an OS advantage to sorafenib (12 vs 16 months, $\mathrm{P}=0.01)$ was observed, consequently temsirolimus is not recommended as a second line therapy. ${ }^{42}$ The RECORD- 1 trial compared everolimus $v s$ placebo in patients progressed or intolerant to VEGF-TKI, a median PFS of 4.9 vs 1.9 months (HR 0.33) was observed but no OS benefit. ${ }^{43}$ The phase II RECORD-3 trial compared everolimus followed by the sunitinib, with sunitinib initial therapy followed by everolimus at progression. The median OS (22.4 vs 29.5 months, HR 1.09) supported the combination of sunitinib followed by everolimus. ${ }^{44}$

\section{Current inclusions to standard therapy}

Nivolumab is a human monoclonal antibody against programmed death receptor-1(PD-1). It blocks the interaction of PD1 with its ligands resulting in enhanced $\mathrm{T}$ cell mediated tumor surveillance. The checkmate 025 trial (phase III) evaluated Nivolumab at a dose of $3 \mathrm{mks} / \mathrm{kg}$ every 2 weeks against everolimus $10 \mathrm{mgs} /$ day in patients with karnofsky performance status of $>70$ and pre-treated with at least 2 prior anti angiogenic agents. CNS metastasis were specifically excluded from the study. This trial showed a significant objective response difference favouring nivolumab (21.5\% vs 3.9\%) that translated into a overall survival benefit of 25 vs 19.6 months (HR 0.73, $\mathrm{P}=0.0018$ ). Nivolumab had a favourable toxicity and quality of life profile than everolimus. Fatigue, nausea and pruritus were the most commonly observed side effectsof nivolumab with treatment discontinuation in only $8 \%$ ( $13 \%$ in everolimus) of patients. Interestingly predictive marker inclusion criteria-based was not applied and the observed benefit noted irrespective of PD-L1 expression status. The above trial formed the basis for approval of nivolumab in 2015 as second line therapy for metastatic renal cancer. ${ }^{45}$

Cabozantinib is an inhibitor or MET, VEGFR and AXL tyrosine kinases. MET and AXL are unregulated as a consequence of VHL gene inactivation in renal cancer and the two have been postulated as possible resistance inducing factors toVEGFR therapy. A phase III RCT(METEOR) compared cabozantinib $50 \mathrm{mgs} /$ day with everolimus $10 \mathrm{mgs} /$ day in advanced renal cancer including those with stable brain metastasis and who had prior therapy. A benefit to cabozantinib over everolimus in the primary end point of
PFS (7.4 vs 3.8 months, P 0.001$)$ was noted with $42 \%$ reduction of disease progression. The results were reproducible in all risk categories and sub groups analysed. Though discontinuation due to adverse drug effects was nearly identical (10\% vs 9\%), dose reductions were $60 \%$ in cabozantinib group compared to $25 \%$ in everolimus arm. Grade 3/4 toxicities were more in the cabazantinib (68\% vs 58\%) with hypertension, fatigue and diarrhoea predominating. All toxicities were managed with dose reductions at $50 \%$ decrements in both arms and only 1 treatment related death reported in each study arm. ${ }^{46}$

Lenvatinib with everolimus is the only combination therapy approved for advanced renal cancer. In a phase II trial on pre-treated patients lenvatinib $18 \mathrm{mgs}$ plus everolimus $5 \mathrm{mgs}$ was tested to either drug as monotherapy. A median PFS of 14, 7.4 and 5.5 months was observed for the combination, levantinib and everolimus respectively, an OS advantage was elusive. The combination arm has more toxicities but all manageable with dose reductions. ${ }^{47}$

\section{Selection of therapy}

The list of approved therapies for advanced renal cancer has rapidly increased in the past decade, but the selection of ideal therapeutic agent for an individual patient is still unclear. Treatment decisions depend upon histological type, risk category and coexistent illnesses. It is important to realise most of the trials that formed the basis for approval of these targeted therapy have excluded non clear cell histology, poor risk category and brain metastasis. It also worthwhile to note that most of the trials that evaluated second line therapy have included non clear cell histology. First line therapy in the non-clear cell group may be initiated with one of the following agents everolimus, temsirolimus or sunitnib. Temsirolimus appears to be the choice in poor risk category while sunitinib, pazopanib and bevacizumab/IFN is recommended as inital therapy in the favourable and intermediate risk category, the ideal among these may be decided by coexistent illness in the individual patient. A tabulated summary of clinical pharmacology of these agents is presented in Table 2. NCCN also recommends high dose IL-2 and sorafenib as first line therapy in carefully selected patients. IFN- $\alpha$ monotherapy has been found to be inferior to sunitinib as first line therapy and hence is no longer recommended. Best results are seen in the nephrectomised patients

Table 3. Selected ongoing trails in advanced RCC.

\begin{tabular}{|c|c|c|c|}
\hline Type & Design & Clinical setting & Status \\
\hline $\begin{array}{l}\text { Phase III } \\
\text { IM motion } 151\end{array}$ & Atezolizumab + bevacizumab $v$ s sunitinib & First line & $\begin{array}{c}\text { Active } \\
\text { Not recruiting }\end{array}$ \\
\hline $\begin{array}{l}\text { Phase III } \\
\text { Checkmate } 214\end{array}$ & Nivolumab + ipilimumab vs sunitinib & First line & $\begin{array}{c}\text { Active } \\
\text { Not recruiting }\end{array}$ \\
\hline $\begin{array}{l}\text { Phase III } \\
\text { Javelin renal } 101\end{array}$ & Avelumab + axitinib vs sunitinib & First line & $\begin{array}{c}\text { Active } \\
\text { Recruiting }\end{array}$ \\
\hline Phase III & Pazopanib for 1 yr $v$ s placebo after metastatectomy & First line & Recruiting \\
\hline Phase II & Pembrolizumab + axitinib vs sunitinib & First line & Recruiting \\
\hline $\begin{array}{l}\text { Phase II } \\
\text { Keynote } 427\end{array}$ & Pembrolizumab in clear cell and non clear cell types & First line & Recruiting \\
\hline Phase II & Metastatectomy in advanced RCC & Curative & Recruiting \\
\hline Phase II & Sunitnib + gemicitabine vs sunitinib in sarcomatous histology & First line & Recruiting \\
\hline Phase II & Pazopanib in non clear cell carcinoma & First line & Recruiting \\
\hline
\end{tabular}


and the sequencing of nephrectomy and targeted therapy in patients presenting with synchronous metastasis is unclear.

Progression after first line therapy requires treatment with one of the following agents cabozantinib, nivolumab, axitinib and lenvatinib/everolimus combination. Progression after cytokine therapy may be treated with any VEGFR inhibitors or mTOR inhibitors or nivolumab, while failure after initial VEGFR therapy requires everolimus, axitinib, sorafenib or other approved agents as above. The ideal sequencing schedule of these agents is still unevaluated. A list on ongoing clinical trials on advanced renal caner is presented in Table 3.

Spurred by the benefits in metastatic disease several trials evaluating the adjuvant role of targeted agents in RCC are underway. The ASSURE and S-TRAC have published their interim results with ASSURE showing no disease free survival benefit but the STRAC showing a benefit particularly in the node positive and high risk cohort. The adjuvant setting continues to be an emerging indication for expanding the role of TKIs in renal carcinoma.

\section{Conclusions}

Survival outcomes for metastatic renal cancer have improved in the past decade particularly with the approval of targeted therapeutic agents. Sequential monotherapy after cytoreductive nephrectomy is the preferred approach but the ideal sequencing strategy of targeted agents remains unknown. Immunotherapy relegated to a selective role is re emerging as an important treatment approach with the licensing of nivolumab. Treatment of progressive disease beyond first and second line therapy is rapidly evolving but despite these optimisms it is important to note these therapies have significant adverse effects and require diligent clinical application.

\section{References}

1. World Cancer Research Fund International. Worldwide data; 2012. Available from: http://www.wcrf.org/int/cancer-factsfigures/worldwide-data

2. World Cancer Research Fund International. Comparing more \& less developed countries; 2012. Available from: http://www.wcrf.org/int/cancer-facts-figures/comparing-moreless-developed-countries

3. World Cancer Research Fund International. Kidney cancer statistics; 2012. Available from: http://www.wcrf.org/int/cancerfacts-figures/data-specific-cancers/kidney-cancer-statistics

4. Gandaglia G, Ravi P, Abdollah F, et al. Contemporary incidence and mortality rates of kidney cancer in the United States. Canad Urol Assoc J 2014;8:247-52.

5. American Cancer Society. What are the key statistics about kidney cancer?; 2017. Available from: https://www.cancer.org/ cancer/kidney-cancer/about/key-statistics.html

6. Reese AC, Whitson JM, Meng MV. Natural history of untreated renal cell carcinoma with venous tumor thrombus. Urol Oncol 2013;31:1305-9.

7. Kroeger N, Pantuck AJ, Wells JC, et al. Characterizing the impact of lymph node metastases on the survival outcome for metastatic renal cell carcinoma patients treated with targeted therapies. Eur Urol 2014; pii: S0302-2838(14)01249-4.

8. DeVita T Jr, Lawrence TS, Rosenberg SA. DeVita Hellman, and Rosenberg's cancer: principles and practice of oncology. Chapter 62. 10th ed. Wolters Kluwer; 2014. pp 857-858.
9. Motzer RJ, Mazumdar M, Bacik J, et al. Survival and prognostic stratification of 670 patients with advanced renal cell carcinoma. J Clin Oncol 1999; 17:2530-40.

10. Mekhail TM, Abou-Jawde RM, Boumerhi G, et al. Validation and extension of the Memorial Sloan-Kettering prognostic factors model for survival in patients with previously untreated metastatic renal cell carcinoma. J Clin Oncol 2005;23:832-41.

11. Negrier S, Escudier B, Gomez F, et al. Prognostic factors of survival and rapid progression in 782 patients with metastatic renal carcinomas treated by cytokines: a report from the Groupe Francais d'Immunotherapie. Ann Oncol 2002;13:1460-8

12. Heng DYC, Xie W, Regan MM, et al. Prognostic factors for overall survival in patients with metastatic renal cell carcinoma treated with vascular endothelial growth factor-targeted agents: results from a large, multicenter study. J Clin Oncol 2009;27:5794-9.

13. Manola J, Royston P, Elson P, et al. Prognostic model for survival in patients with metastatic renal cell carcinoma: results from the International Kidney Cancer Working Group. Clin Cancer Res 2011;17:5443-50.

14. Heng DY, Xie W, Bjarnason GA, et al. Progression-free survival as a predictor of overall survival in metastatic renal cell carcinoma treated with contemporary targeted therapy. Cancer 2011;117:2637-42.

15. Flanigan RC, Salmon SE, Blumenstein BA, et al. Nephrectomy followed by interferon alfa-2b compared with interferon alfa- $2 \mathrm{~b}$ alone for metastatic renal-cell cancer. $\mathrm{N}$ Engl J Med 2001;345:1655-9.

16. Mickisch GH, Garin A, Madej M, et al. Tumor nephrectomy plus Interferon $\alpha$ is superior to Interferon $\alpha$ alone in metastatic renal cell carcinoma. J Urol 2000;163:176.

17. Fyfe G, Fisher RI, Rosenberg SA, et al. Results of treatment of 255 patients with metastatic renal cell carcinoma who received high-dose recombinant interleukin-2 therapy. J Clin Oncol 1995;13:688-96.

18. Abdollah F, Sun M, Thuret R, et al. Mortality and morbidity after cytoreductive nephrectomy for metastatic renal cell carcinoma: a population-based study. Ann Surg Oncol 2011;18:2988.

19. DeVita T Jr, Lawrence TS, Rosenberg SA. DeVita Hellman, and Rosenberg's cancer: principles and practice of oncology. Chapter 63. 10th ed. Wolters Kluwer; 2014. pp 876-882.

20. Choueiri TK, Xie W, Kollmannsberger C, et al. The impact of cytoreductive nephrectomy on survival of patients with metastatic renal cell carcinoma receiving vascular endothelial growth factor targeted therapy. J Urol 2011;185:60-6.

21. George CM, Vogelzang NJ, Rini BI, et al. A phase II trial of weekly intravenous gemcitabine and cisplatin with continuous infusion fluorouracil in patients with metastatic renal cell carcinoma. Ann Oncol 2002;13:116-20.

22. Gore ME, Griffin CL, Hancock B, et al. Interferon alfa-2a versus combination therapy with interferon alfa-2a, interleukin-2, and fl uorouracil in patients with untreated metastatic renal cell carcinoma. Lancet 2010;375:641-8.

23. Sternberg CN, Davis ID, Mardiak J, et al. Pazopanib in locally advanced or metastatic renal cell carcinoma: results of a randomized phase III trial. J Clin Oncol 2010;28:1061-8.

24. Motzer RJ, Hutson TE, Cella D, Reeves J, et al. Pazopanib versus sunitinib in metastatic renal-cell carcinoma. N Engl J Med 2013;369:722-31.

25. Escudier B, Porta C, Bono P, et al. Randomized, controlled, double-blind, cross-over trial assessing treatment preference for pazopanib versus sunitinib in patients with metastatic renal 
cell carcinoma: PISCES Study. J Clin Oncol 2014;32:1412-8.

26. Motzer RJ, Hutson TE, Tomczak P, et al. Sunitinib versus interferon alfa in metastatic renal-cell carcinoma. N Engl J Med 2007;356:115-24.

27. Motzer RJ, Hutson TE, Olsen MR, et al. Randomized phase II trial of sunitinib on an intermittent versus continuous dosing schedule as first-line therapy for advanced renal cell carcinoma. J Clin Oncol 2012;30:1371-7.

28. Lee JL, Kim MK, Park I, et al. Randomized phase 2 trial of sunitinib four weeks on and two weeks off versus two weeks on and one week off in metastatic clear-cell type renal cell carcinoma: RESTORE trial. Ann Oncol 2015;26:2300-5.

29. Escudier B, Eisen T, Stadler WM, et al. Sorafenib in advanced clear-cell renal-cell carcinoma. N Engl J Med 2007;356:12534.

30. Escudier B, Eisen T, Stadler WM, et al. Sorafenib for treatment of renal cell carcinoma: final efficacy and safety results of the phase III treatment approaches in renal cancer global evaluation trial. J Clin Oncol 2009;27:3312-8.

31. Jäger D, Ma JH, Mardiak J, et al. Sorafenib treatment of advanced renal cell carcinoma patients in daily practice: the large International PREDICT Study. Clin Genitourin Cancer 2015;13:156-64.e1.

32. Escudier B, Szczylik C, Hutson TE, et al. Randomized phase ii trial of first-line treatment with sorafenib versus interferon alfa-2a in patients with metastatic renal cell carcinoma. J Clin Oncol 2009;27:1280-9.

33. Motzer RJ, Nosov D, Eisen T, et al. Tivozanib versus sorafenib as initial targeted therapy for patients with metastatic renal cell carcinoma: results from a phase III trial. J Clin Oncol 2013;31:3791-9.

34. Motzer RJ, Porta C, Vogelzang NJ, et al. Dovitinib versus sorafenib for third-line targeted treatment of patients with metastatic renal cell carcinoma: an open-label, randomised phase 3 trial. Lancet Oncol 2014;15:286-96.

35. Escudier B, Bellmunt J, Négrier N, et al. Phase III trial of bevacizumab plus interferon alfa-2a in patients with metastatic renal cell carcinoma (AVOREN): final analysis of overall survival. J Clin Oncol 2010;28:2144-50.

36. Halabi J, Rosenberg W, Stadler M, et al. Bevacizumab plus interferon alfa compared with interferon alfa monotherapy in patients with metastatic renal cell carcinoma: CALGB 90206. Clin Oncol 2008;33:5422-8.
37. Bukowski RM, Kabbinavar FF, Figlin RA, et al. Randomized phase II study of erlotinib combined with bevacizumab compared with bevacizumab alone in metastatic renal cell cancer. J Clin Oncol 2007;25:4536-41.

38. Rini BI, Escudier B, Tomczak P, et al. Comparative effectiveness of axitinib versus sorafenib in advanced renal cell carcinoma (AXIS): a randomised phase 3 trial. Lancet 2011;378:1931-9.

39. Rini BI, Wilding G, Hudes G, et al. Phase II study of axitinib in sorafenib-refractory metastatic renal cell carcinoma. J Clin Oncol 2009;27:4462-8.

40. Hutson TE, Lesovoy V, Al-Shukri S, et al. Axitinib versus sorafenib as first-line therapy in patients with metastatic renalcell carcinoma: a randomised open-label phase 3 trial. Lancet Oncol 2013; 14:1287-94.

41. Hudes G, Carducci M, Tomczak P, Dutcher J. Global ARCC Trial, Temsirolimus, interferon alfa, or both for advanced renal-cell carcinoma. N Engl J Med 2007;356:2271-81.

42. Hutson TE, Escudier B, Esteban E, et al. Randomized phase III trial of temsirolimus versus sorafenib as second-line therapy after sunitinib in patients with metastatic renal cell carcinoma. J Clin Oncol 2014;32:760-7.

43. Motzer RJ, Escudier B, Oudard S, et al. RECORD-1 Study Group Phase 3 trial of everolimus for metastatic renal cell carcinoma: final results and analysis of prognostic factors. Cancer 2010;116:4256-65.

44. Motzer RJ, Barrios CH, Kim TM, et al. Phase II randomized trial comparing sequential first-line everolimus and secondline sunitinib versus first-line sunitinib and second-line everolimus in patients with metastatic renal cell carcinoma. J Clin Oncol 2014;32:2765-72.

45. Motzer RJ, Escudier B, McDermott DF, et al. Nivolumab versus everolimus in advanced renal-cell carcinoma. N Engl J Med 2015;373:1803-13.

46. Choueiri TK, Escudier B, Motzer RJ, et al. Cabozantinib versus everolimus in advanced renal-cell carcinoma. N Engl J Med 2015;373:1814.

47. Motzer RJ, Hutson TE, Glen H, et al. Lenvatinib, everolimus, and the combination in patients with metastatic renal cell carcinoma, a randomised, phase 2, open-label, multicentre trial. Lancet Oncol 2015;16:1473-82. 